\title{
Creating ungoogleable learning experiences: an experiment with a course in motor development
}

\author{
MARCIO A. OLIVEIRA ${ }^{1}$
}

${ }^{1}$ Assistant Vice President Academic Technology \& Innovation - Teaching \& Learning Transformation Center University of Maryland, College Park, Maryland, United State of America.

Correspondence to: Teaching \& Learning Transformation Center; 4131 Campus Drive, College Park, MD 20742, USA.

email: marcio@umd.edu

https://doi.org/10.20338/bjmb.v15i5.262

$\begin{array}{ll}\text { ABBREVIATIONS } \\ \text { LMS } & \text { Learning management system } \\ \text { OER } & \text { Open Educational Resources } \\ \text { TA } & \text { Teaching assistant } \\ \text { UMD } & \text { University of Maryland }\end{array}$

PUBLICATION DATA

Received 13102021

Accepted 28112021

Published 01122021

\begin{abstract}
As we progress towards the middle of the 21 st century, we should ask ourselves: what kind of education is going to be worth our students' commitment of time, energy, and money? At the same time, higher education institutions ought to reconceptualize how to prioritize their investment and use of their limited resources. More than ever, we are being forced to reimagine the way we teach and how education will meaningfully relate to the future professional success and civic engagement of our students. In this paper, I share a period of my instructional experience during which I continually innovated a course in the field of motor behavior. While the work reported in this article refers to insights and improvements made in an undergraduate course about the development of human motor behaviors, others might draw on ideas and, eventually, adapt them to different subject areas and/or co-related disciplines. This manuscript did not result from systematic educational research, nor are the strategies and outcomes included meant to be conclusive or generalized. This is a personal testimonial about part of my journey as an educator and, hopefully, an important reminder that science and education co-exist and must be equally valued in academe. Ultimately, our educational practices are the fundamental source of inspiration for the new generations and, probably, the key element in keeping our science alive.
\end{abstract}

KEYWORDS: Motor development | Teaching | Learning | Flipped classroom

\section{INTRODUCTION}

Approximately twelve years ago, a student taking one of my courses came to my office hours and candidly shared that she was feeling like her experience in the classroom was akin to being in a distance education course, even though she had never missed one day of instruction in the classroom. I was a bit surprised, and immediately asked her why she was feeling that way. She was excited about the course, but wished to have more opportunities to interact, ask questions, and have more in-depth discussions about the different topics that I introduced to the class. This was a large enrollment class where my primary concern was to cover all the content planned in the syllabus. During my conversation with the student, I quickly realized how passive her learning experience in the classroom was. Her comments immediately started my thinking about changes that I could make in my teaching strategies to cover the content without sacrificing opportunities for my students to engage with their peers and myself during class time. Before she left my office, I sincerely thanked her for speaking up and promised that I would continue to challenge myself to improve the ways I teach.

This was a course in motor development--a three-credit requirement in the bachelor of science degree in kinesiology at the University of Maryland (UMD). The kinesiology program provides a well-rounded, scholarly understanding of human movement and physical activity. The overarching goal of this particular course was an 
understanding of the developmental processes that underlie movement coordination and control across the lifespan. I taught this course at UMD every semester from 2006 to 2014, along with two teaching assistants. Approximately 180 students took this course each semester. The students were typically interested in a variety of medical and allied health professions including, but not limited to: physical therapy, medicine, speech therapy, nursing, occupational therapy, gerontology, athletic training, and physical education. The weekly course schedule included two 50-minute lecture sessions, led by the instructor, and a 50-minute laboratory session for groups of 20 students, led by a teaching assistant (TA).

The lab sessions were planned to be small in size, interactive, and include active learning opportunities. However, due to the class size and time constraints, students indeed had fewer opportunities to engage with the instructor and each other while attending sessions in the large lecture hall. Despite my attempts to purposefully implement technology tools such as "clicker" polling and mobile device use to increase engagement during my lecture sessions, it was always a challenge to identify opportunities for the students to reflect on what they were learning, relate it to past experiences, and apply it to their daily lives. This was both unfortunate and frustrating, because learning motor development requires structured practices where the "student's eyes" need to be welltrained to critically observe behaviors and, at the same time, analyze the underlying mechanisms that influence cognitive-behavioral changes across the lifespan.

In 2010, during the fall semester, I decided to "flip" this course for the very first time. A flipped classroom model 1,2 is an instructional strategy and a type of blended learning that aims to increase students' engagement and learning by encouraging them to study course materials asynchronously, prior to attending a live class session with the instructor. This model allows instructors to move activities that may have typically been considered laboratory or homework into the classroom. In a flipped class, students watch online lectures, collaborate in virtual discussion boards, or carry out learning activities and assignments remotely while engaging more in-depth in concepts when in the classroom with the guidance of the instructor. This article details my first attempt to compile and share some pedagogical choices that I have made across the years to flip my class and make the learning experience in the classroom "ungoogleable," a term I have come to use to describe practices that are both highly engaging and meaningful to my students-something they cannot get by simply researching a topic online. The student-centered strategies described in this manuscript reflect my instructional journey to continually transform this course. The article concludes with a few lessons learned over the years. The ideas described here do not follow a chronological order. Rather, they represent a collection of "experiments" undertaken across several semesters adopting blended and fully online strategies that have proven to be effective based on the literature ${ }^{3-6}$ and the feedback received from students. ${ }^{7}$

\section{BLENDING IN-PERSON AND REMOTE LEARNING ACTIVITIES}

One of the major conceptual shifts that happened in the course was that I fully embraced that instruction, learning activities, and assessments could be successfully conducted through a combination of in-person and remote activities. Recognizing that my students could learn a lot without my presence motivated me to explore ways to increase opportunities for them to discuss, reflect, debate, and analyze the course content. Hence, I 
decided to trade off 50 minutes of "seat-time" in the classroom with content, activities, and small formative assessments that were delivered asynchronously and remotely through the campus learning management system (LMS). When this decision was made and approved by the program administrators, a brand-new course structure was created. The weekly schedule was redesigned to include remote pre-class assignments, an in-class live dialogue, and a post-class follow-up activity, which was accomplished with a TA-guided lab session and assignment.

Remote pre-class assignments consisted of watching a video lecture and completing an online quiz prior to attending the in-person session in the classroom. This way, the content was delivered through video lessons and basic understanding was verified through an online quiz. During my first attempt to create the instructional videos, I simply digitized my lectures and provided the students with a voice-over PowerPoint video file that was approximately 50 minutes long. Students were encouraged to watch me going through the slides and listen to my explanations remotely and asynchronously. After a few weeks using this approach, I learned that, while the students greatly appreciated the fact that they could watch the videos at anytime and anywhere, pause to take notes, and replay them as necessary, many mentioned that it was difficult to stay engaged because the videos were too long. In response to this feedback, I started to record new videos that were scripted, reduced in length (8-12 minutes maximum), and more engaging than just a sequence of PowerPoint slides. I decided not to use PowerPoints at all and, instead, the recording included me teaching "in action" on the screen (not just my voice), along with elaborated animations and visuals such as pictures, diagrams, charts, symbolic arrows, etc. to complement my explanations. While the preparation of these materials was timeconsuming, it was extremely rewarding. The students responded well to the new media material produced, not just because it was not a static PowerPoint, but also because the information was delivered in a very precise, animated, relatable, and intentional way. The video scripts helped me avoid redundancies and deviations from the main topics, keeping the videos short. I also used the scripts to add closed captioning, allowing all the students (not only those that required accommodations) to fully experience the video program without having to actually hear the audio track. The use of closed captions is also known as helpful to L2 learners and those with auditory processing challenges.

Weekly quizzes were required and originally intended to ensure that students understood the content shared through the videos prior to coming to the class in-person session. I typically designed ten questions per week and used them as a formative assessment in the course. In the beginning, I included simple questions in which students could just prove that they had a basic understanding of the information presented in the videos. I assumed that the content shared through the videos was enough to spark the students' curiosity and generate questions. However, this was not the case; the students were not coming to class interested in learning more, intrigued, or with more elaborated questions. After discussing this with them and after a few iterations, I started to use the weekly quizzes to advance their understanding and provoke a bit of discussion. I redesigned the questions in a way that they had to apply, analyze, and evaluate the information shared in the videos. These new questions had a higher level of complexity and required higher-order thinking skills, which led the students to be more critical and curious about the information that was presented. The weekly quizzes were worth five percent of the final grade and automatically became unavailable every Tuesday at 
midnight. This established a deadline for the quiz a day before the class, making the students better prepared for the in-class dialogue scheduled for every Wednesday. The students' engagement with the course content changed dramatically, and some students started to send questions by email immediately after finishing their quizzes, suggesting topics and issues that they wanted to be addressed on the next day when we met in person. I found that the combination of these two weekly activities (short videos + a tenquestion quiz) as pre-class assignments was paramount to the successful flipped model, because it helped the students to stay asynchronously engaged and on track with the planned course schedule.

\section{EXPANDING ASYNCHRONOUS LEARNING OPPORTUNITIES}

One day, another student approached me at the end of a class session and asked if I could share with him the audio files used in my videos. I was curious and asked why he wanted audio files and how he was planning to use them. He said: "I usually watch your videos once to take the weekly mandatory quizzes. However, when I feel the need to review the content again or study for your midterm or final exams, I like to play the videos on my phone and simply listen to your explanations while I am on the bus or in transit around campus--I really do not feel the need to watch your videos again, but I benefit a lot from just listening to them". This student inquiry made me realize that I was wrong to assume that all my students needed those elaborated visuals. Not all students learn the same way, and I was missing the opportunity to explore and diversify ways in which course content could be delivered and experienced. Most importantly, I realized that I could provide students with options and let each student decide which forms were most appropriate and beneficial to their own learning. I already had not only the audio files for all the videos, but also the scripts that could be made available to all of the students. I edited the audio files to make them podcast-like and also made the scripts available to them. This way, they did not need to spend time taking notes about the basic course content while watching the videos or listening to the podcasts, freeing up the cognitive load to be used in high-level and critical thinking.

When I brought these options up for discussion with my students in class, it was clear, and almost unanimous, that they all could greatly benefit from having a myriad of asynchronous and remote learning options with which they could explore their greatest ability to read, listen, watch, practice, review, or even reconstruct course content. From that day onwards, a new era of this course began. I started to intentionally provide the students with options and opportunities to take advantage of auditory and visual channels in working memory to learn. Interestingly, I felt that this approach allowed students to be more accountable for their own learning processes since they now had autonomy in their preferred/best learning style. Additionally, I suggested to those who were having challenges that they explore different ways of engaging with content and choose one that they would consider more effective. All students had access to all the different learning resources throughout the semester. At any time, they could go back and review any material.

I also began to explore the use of different types of materials that I had not originally developed for this course. I strategically leveraged the amount of content already available on the internet by selecting, curating, and deploying resources beyond scientific 
papers on motor development. This included interviews posted on YouTube or Vimeo, related magazine articles, documentaries, clinical cases, websites, blogs, etc. I created a section in the LMS called "internet resources" that had optional content available for the students to expand and supplement their learning opportunities in the course. As an educator, I found that it was a big mistake to ignore that internet searches were a part of everyday life for students. I sought out ways to integrate such resources into my pedagogical practices. I implemented them not only to expand and diversify my course materials but also to help the students explore lifelong learning opportunities. It did not take long for the students to also start googling for complementary information and to send links for me to add to this LMS section. However, when I started to look carefully at the links they shared, I found that while some were really great, others were not. Much of what was being submitted was not evidence-based nor examples that I would choose to showcase principles and research findings discussed in class. I was disappointed by how much "blundered information," "fake-news," and/or misinformation was published on the internet.

I spent some time reflecting on how to integrate these materials that I initially considered "useless." I quickly realized that I could mold them into my course activities as a way to test whether my students were really learning the theoretical and scientific concepts that I was teaching in the course. I finally came to a conclusion that: a) the internet is a common and great source of learning-it is easily accessible to our students and abundant in content across all subject areas; b) there is plenty of information (text, videos, podcasts, blogs, images, etc.) that claims to be based on scientific findings, but is not, and this (in my opinion) could be one of the best sources of lifelong learning if properly adopted in the context of the class; and, c) the internet provides boundless ways to explore and integrate higher levels of learning, such as to analyze and evaluate what is being learned, and ultimately create and share new information produced by the students.

I used this opportunity to integrate Google searches as part of the learning practice and started using their findings in our lab sessions led by the TAs. As part of the post-class follow-up assignment, students were asked to search for misleading information on the internet. Once they identified a publicly available piece on the internet that included anecdotal findings, they were asked to write a critique or to recreate the same piece of information making it more reliable based on the theoretical concepts and scientific principles that they had learned in class. This strategy gave the students broader opportunities to discuss, reflect, debate, and analyze information. Our pedagogical strategies began to shift from an information-giving learning model to an applied, activecritical model. The adoption of this strategy also increased the students' participation in our large class sessions, because it not only allowed them to be better informed but also required them to critically discriminate and fully utilize the overwhelming amount of information that was freely accessible to them. In addition, I was engaging them in ways that were real and meaningful to our students' lives by providing opportunities in which students could critically talk, write, relate, and apply what they were learning.

\section{CHANGING THE WAY STUDENTS' LEARNING IS ASSESSED}

There is no doubt that after shifting the way I was teaching, and thereby the processes by which the students were learning, I was compelled to ensure that the 
assessments were accurately designed to reflect the students' learning ability in this course. But changing the way I assessed learning was no simple task. During the initial semesters, I kept the same type of midterm and final exams, which included a series of multiple-choice questions. In fact, I intentionally used the same type of questions adopted in previous semesters to benchmark the students' grades and to gauge the impact of the pedagogical changes that I was making. I was expecting a decrease in the percentage of students earning grades below average or failing the course, which typically comprised about $10 \%$ of students during any given semester.

After administering a few exams and not seeing a shift in outcomes as I expected, the students started to express a great level of frustration and the sentiment that they felt unfairly treated in the course. Many of them would come to me stating that they were super excited to learn, feeling actively engaged with all course activities, but they were really upset because their grades on exams were not reflecting the amount of time they had invested in learning the course content. They also did not think that the grade breakdown was fair, because the midterm and final exams accounted for the greatest portion of their final grade. According to my students, despite all their efforts to stay on track, succeed in all the formative pre-class assignments, participate in all lab sessions, and successfully complete their post-class assignments, they were not performing well on the exams and were getting low final grades. Some of them were even feeling at the risk of failing the course.

Following many attempts, I was convinced that I needed more than just slight adjustments to the multiple-choice questions on my exams. All the student-centered strategies that were being adopted to promote learning were basically conflicting with a conventional method of testing. Most of the time, I was encouraging the students to apply, analyze, evaluate, or even create their own materials during the semester. However, the questions included on the exam were perceived as disassociated from these experiences, requiring simple memorization of detailed information presented to them. I was puzzled. As an instructor, I wanted them to remember what was being taught, and I could not clearly identify the disconnect between the way I was teaching and the way I was assessing their learning. In my opinion, they were well prepared to answer all of the questions contained within the midterms and finals, but they were clearly not performing as well as either of us expected. Because flipped learning is more decentralized and personalized than a traditional course design, the real challenge I faced was how to design exams that provide reliable, applied, and actionable outcomes that could accurately and better reflect students' learning beyond memorization.

After discussing the assessment disconnect with several students and my TAs, it became clear that, while the primary goal of our face-to-face sections was to translate knowledge to the "real world," the midterm and final exams were not providing adequate opportunities for our students to do so. Despite all efforts to change the structure of the class and to put students in a position to learn in expanded ways, the exams were not aligned with my instructional principles and, therefore, hindered students' success. I challenged myself to completely redesign the exams but in a principled manner. I kept the same questions (content-wise) but contextualized them into scenarios and situations extracted from the real world. For example, I designed a midterm exam focused on perceptual development with exactly the same questions that I used before, but the questions were logically integrated into a narrative in which I described the early 
developmental processes and milestones of a deaf child who was impacted by teratogens during the prenatal period. The exam was presented as a case study, and questions were posed along with the explanation of the child's developmental process. In this particular case, as the child achieved developmental milestones, new behaviors emerged and related questions were being presented. This was a game-changer and proved to be extremely successful. I received great feedback from the students stating that they had a much better understanding of the same questions and were feeling much better prepared to answer them. By making this crucial adjustment, students were able to delve into the exact same questions, but within a given context/scenario, reproducing what we were doing during our class and lab sessions. Cognitively, the students were being led to use their metacognitive knowledge to answer the same questions but adopting similar mental strategies practiced in class.

I also developed a framework for classifying and associating letters to each question on the exam. This was done to help guide the students and connect the questions and the learning resources made available in the course. For example, the letter "M" was assigned to course materials posted on the LMS, questions drawn from lab activities were assigned the letter "L," and questions extracted from quizzes were assigned the letter "Q." The main reason why I adopted this classification was that I wanted them to understand that the exams were designed to demand different hierarchical levels of cognitive skills and the questions were carefully crafted to include many levels of complexity and specificity. To this end, I also associated the letter " $A$ " with questions that required advanced levels of understanding and critical thinking. This strategy helped me to balance the amount and type of questions included in each exam and also helped the students to manage their expectations and better understand how to study for the exam. Ultimately, if the students were not able to respond correctly to the "A" questions, they would know that they most likely would not end up with high final grades in the course.

Further, to reduce the amount of memorization, and to increase their confidence, students were allowed to bring a handwritten (not typed/printed) standardized notecard (5x7 inches) that they could prepare ahead of time and include any information they wanted. I learned that this basic practice not only helped during the exam but also helped them to study and reinforce key points before the high-stake exams. The use of a notecard was nothing new. It has been well known as a way to alleviate the students' stress and place their focus on applying strategies rather than just memorizing information.

\section{CREATING A MODULAR AND ELASTIC COURSE STRUCTURE}

After designing materials that could be used to teach different course modalities (in person, fully online, or blended/flipped), I ended up with a vast diversity of learning materials and different types of assessments. Although these materials were organized by instructional modalities and by semesters, my ability to maintain and update the extensive set of electronic files across several semesters became a major challenge. To address this issue, I decided to create a master course organized into modules. I identified buckets that contained video lectures, readings, discussion boards, quizzes, assignments, weblinks, etc., all combined around specific topic areas and respective learning outcomes. The modules were focused on critical pieces of the skills and not the coverage of content. Like a textbook in which all chapters follow a similar didactical way to instruct, the modules 
were designed as independent learning units that followed a consistent logic and also balanced the amount of time, workload, and components needed to help guide students to recognize the big ideas and areas.

I also used the modules to create a learning narrative across the semester allowing me the flexibility to deploy them, regardless of the mode of delivery and course duration (15 weeks, 6 weeks, or even 3 weeks long). For instance, in a more traditional (inperson) course, the modules were designed, by default, to be deployed once per week. However, when the course was being taught entirely asynchronously online during the summer or winter semesters, I was able to quickly adjust the overall schedule and deadlines by delivering two or three modules per week. Because the modules were built with a consistent structure (the length of time, the amount of work, and the due dates of quizzes and assignments), the students were able to organize themselves better to succeed. At the beginning of the semester, they had a clear idea of what was expected of them on a week-to-week basis. In addition, by keeping a consistent pattern of due dates for quizzes and assignments in each module, the students were given a predictive structure that helped with generating accountability and ensuring the completion of course requirements in a timely manner.

I fully understood that each course and discipline has its particularities, overarching goals, learning outcomes, and strategies. Nonetheless, my experience organizing this course into modules was extremely helpful and, in my opinion, worth sharing, not only because this gave me an effective and elastic structure that was easier to manage and update, but also because the students found it easier to navigate throughout the course materials. This approach helped my students to manage their time and, most importantly, to know ahead of time what to expect in terms of course workload.

\section{SHARING INSTRUCTIONAL ASSUMPTIONS AND EXPECTATIONS}

In general, instructors take for granted that the course syllabus provides all the information that students need throughout the semester to be successful. While the learning outcomes were clearly defined for the course in the syllabus, I quickly learned, after my first attempt to flip my class, that the blended modality was new to many. Therefore, I felt strongly compelled to take time at the beginning of the semester to establish a clear and mutual understanding between my students and myself. I reasoned that I needed to go beyond my typical overview of the course syllabus, content, learning outcomes, resources, and guidelines. It became crucial (and I improved this strategy after a few semesters) to set the stage and explain to my students my pedagogical choices, and what it takes to be successful in a blended/flipped course.

During the first class session, I included an explanation of the flipped model and the thought process that led me to restructure this course. I also included a discussion of what I started to call our "Learning Agreement" in which I detailed our shared responsibilities, explained my assumptions about their individual learning process, and also managed the expectations related to our levels of commitment and engagement throughout the semester. Although this seems a bit obvious to many, from an instructional perspective, it is very important not to simply assume that the students understand well what has been planned for the semester. I found it extremely helpful to explain, in detail, how the course was structured, provide them with a rationale, and give them a chance to 
ask questions and express concerns at the beginning of the semester, so adjustments could be made. In this context, we also discussed shared values and, most importantly, justified why some choices were made around content delivery, deadlines, communications, class engagement, and assessments.

For instance, I took the necessary time at the beginning of the semester to create a shared understanding that learning happens inside their minds and that my role, as the instructor, was to guide them throughout this individualized process by triggering curiosity and inspiring them to learn. I explained that the in-person experiences in the classroom and in the laboratory were designed to be "ungoogleable moments" in which most of the time spent together was on higher-order thinking skills. With the help of their colleagues, the TAs, and myself, we would engage ourselves in problem-finding, collaboration, design, problem-solving, group work, research, and constructing knowledge. Most of the synchronous time would be collectively spent addressing the students' questions, introducing real-life scenarios in which the content was closely applied (e.g., clinical, educational, therapeutic, or daily-life cases), and asking the students challenging (deeper) questions to reinforce critical concepts and further their understanding in a meaningful way.

Some social norms for the course were also agreed upon. For example, everyone was welcome to bring and use their mobile devices. This was interesting, not just because they were taking and sharing electronic notes during the class, but also because when a student asked me a question, I would purposefully ask another student who was browsing on the internet to search that question and share with everyone the answers that appeared on the top three hits on Google. This practice alone generated interesting discussions and, most importantly, sparked lively engagements while we learned together in a large classroom.

The fact that a class could take an unexpected direction required some level of vulnerability from me as the instructor. However, I felt that I was honoring where they were in their learning process at that moment. It also helped to erode away the "Sage on the Stage" approach to instruction, reducing the students' expectations that I knew all things at all times. At the beginning of each semester, I positioned myself as an expert facilitator of learning and was very comfortable telling them I was a researcher and a proud lifelong learner in the field of motor development--the main difference between us was the fact that I started to study the field a few years before.

The students also leveraged the use of laptops and mobile devices inside the classroom to take notes collaboratively in real-time by using digital tools, such as Google Docs, which were freely accessible to them. Other examples of social norms suggested by the students were to avoid disrupting others by displaying random and unrelated content on their laptop screens. Additionally, some students wanted us to agree on a timeline in which feedback on assignments and grades were reported back to them. Attendance was not required in the classroom, but participation in lab sessions was.

Core values were also introduced as part of the learning agreement and were critical for the course. We typically agreed on four shared class values. First, integrity: one should never take credit for other people's work. Avoid repeating others' work--rather build upon others' work. Second, engagement: group work was to be constructive, participatory, productive, and open-minded. Everyone would always make an effort to move the discussion and project forward. We would all agree to communicate in a timely and professional manner with each other and provide candid feedback as needed. Individual 
grades were to be confidentially shared in a timely manner. Third, commitment: class started and ended on time and deadlines were to be consistently met with no exceptions and rare excuses. Finally, respect: we agreed to actively listen to understand others and to be considerate and respectful of everyone's ideas. We would welcome and value different perspectives. Everyone in class would get to be right and/or wrong without assumptions and judgments.

After sharing these course values with the students, it was clear to everyone that we could only thrive in a learning environment in which we all could feel free to ask questions, freely participate in class discussions, and challenge ourselves and each other. We were collectively creating what we consider an exceptional learning experience by promoting self-efficacy amongst a diverse group of learners and uniquely embracing the use of technology to improve their experience.

\section{GAUGING IMPACT AND GATHERING FORMAL FEEDBACK}

During the fall semester of 2012, I formally surveyed 250 students to gather feedback about students' experiences in my course in a more systematic way. In the middle of the semester, students were asked to answer a brief anonymous questionnaire online and encouraged to be as candid as possible. I mentioned that I was reflecting a lot about the adoption of the flipped learning model and was planning to make additional changes. I also explained that their feedback would be critical to guide me through my future choices and decisions.

About 180 students responded to the mid-semester survey and, in general, the participation rate and results were both impressive and revealing. Seventy-three percent of the students reported that the flipped classroom model was effective. Seventeen percent of the students were indifferent, and $9.6 \%$ said that they did not think that this method was effective. Upon review of the qualitative comments within the survey, I found that some students preferred the more traditional model of teaching, because they perceived it as less work on their end. Some students indicated that they were used to and felt well trained in memorizing content. These students were not as interested as others in taking this required course and just wanted to meet their graduation requirements. Sixty-seven percent of the students confirmed that they watched the instructional videos or engaged with course materials provided to them more than once in order to review and study for the midterms and final exams. Eighty-four percent of students completely agreed that the weekly mandatory quizzes were extremely beneficial to their learning and, most importantly, helped them to manage their schedule and allocate their overall time through the week to stay on track with the course schedule. Sixty percent of students stated that the flipped model allowed them to self-pace their studying and felt that having control of their time to learn helped them to succeed in the course. When asked questions about their overall learning experience in the course, the majority of the students (87\%) reported that they would take another class using the blended/flipped model. They also mentioned that this type of model did not make them spend more time than they would in a more traditional course modality.

The university also encouraged the students to participate in an online, campuswide course evaluation system that is released at the end of each semester. The instrument includes fifteen questions, seven student-interest and eight administrative- 
interest; responses to the former are ultimately seen by only students and the instructor, while responses to the latter are made available to administrators. Access to results is driven by participation. Students see reports only when $70 \%$ or more of a course's students complete the evaluation and only if they have completed evaluations for the courses they have taken (this is waived for new students). The university distributes automatic email notifications when the evaluation system is live, instructing students and instructors on the process. Interestingly, the results of the course evaluations also reflected the course design change. One of the most striking data points from Fall 2014 was that $94.9 \%$ of students strongly agreed that "overall the instructor was an effective teacher." This was a $25 \%$ increase from a previous semester in which a more traditional lecture-like approach was used to teach the same course. Important to note is that this particular data point is strategically used by the unit and program administrators to verify teaching effectiveness and also to assess the need to provide additional instructional support and professional development opportunities to those that were not well perceived as effective teachers by the students.

\section{IDENTIFYING AND TRANSFERRING BEST PRACTICES}

As I reflect back on what was accomplished and learned from this process to reimagine my course, I am proud and confident to report that the choices that I made have dramatically improved the quality of the students' learning. During this transformational period, I explored new ideas, experimented with new strategies, failed many times, and succeeded in many different and exciting ways. After restructuring the course by using the blended/flipped model, I never went back to the more traditional way of teaching. When I was asked by academic administrative leaders and colleagues from different areas to share my best practices, I usually summarized my talking points around the following ten tips:

\section{Flip a classroom only if you want the students to take ownership of their learning}

There are many ways and reasons why one would want to mix in-person and remote course activities. However, the main reason, and perhaps the only one, should be because this integrated approach would expand the students' learning opportunities and improve the quality of their experiences. This method allows them to explore ways to learn that they may not have had the opportunity to explore in a traditional model.

\section{Be willing to flip your mind}

Agreeing that learning happens in the students' minds also means agreeing that the students also learn when you (the instructor) are not physically present. I consider this to be one of the biggest challenges of implementing the new strategies of a flipped model in your course. It requires a deep self-assessment of your role as instructor and forces you into a thoughtful analysis of your "teaching" methods--a profound reflection on the role(s) of the instructor inside the classroom.

\section{Remember that pedagogy drives and technology accelerates}

One should not implement learning technology tools into a course only because this is the contemporary way of teaching, or because it would save time. Technology- 
based resources are great only if they play a supporting role in instruction and if they strategically facilitate and enhance students' engagement and learning. In addition, instructors should keep in mind that technology may not always work when it is needed. Be flexible, willing to troubleshoot technical difficulties with your students, and always have a backup plan.

\section{Plan ahead}

The additional time and effort that is needed for this kind of effort will pay off later on. One may be concerned that this will take too much time and that no one gets additional institutional "incentives" to flip a course. I have learned, very quickly, that all the additional time and effort that I put into flipping my classroom paid off during the first weeks of the semester. Among several benefits, the first, and most rewarding, was the students' higher level of engagement and the quality of their questions. Be certain that the majority of the students would be willing to be part of a newly designed learning experience and would be open to trying new ways to learn. They will also rapidly perceive that the main reason why you are flipping the course is that you care for their learning process much more than you care for your teaching experience and expertise.

\section{Be willing to take risks and be ready to fail}

Transformation takes more than ideas, and failure is a critical part of the innovation process. There are endless ways to learn and flip a course. Plan your course thinking about what "teaching and student learning" will mean ten or twenty years from now. Be as creative as you can. Think out-of-the-box, and come up with formal and informal strategies that were never thought of as possible within the traditional academic environment. During the process of trying new strategies, give failure a chance. You will not get it right all the time. Finding out that some choices are useless is part of the creative and transformative process.

\section{Be mindful and programmatic}

Take baby steps. As you plan new strategies to flip a course, implement them in phases, perhaps a course module or unit at a time. Do not make a lot of changes and try them all at once, especially if you are planning the use of new technologies. Think broadly, as if you had no constraints to reach the course objectives, then share the new idea with the students and find the best strategy to meet their learning needs. Make big plans, but solidly conquer each of your goals step by step. Fundamentally, enjoy the experience of learning as you design your course and teach it.

\section{Use the LMS as a learning portal}

Since every course nowadays is technology-enhanced, and may be hosted in an institutional LMS, I suggest that instructors think about their students, and not about themselves, while designing the virtual course space. Think of the user experience while your students are studying alone, asynchronously, and remotely. Students should have minimum difficulties in navigating throughout the digital modules, pages, and materials designed for them. The course must have a consistent structure (unit titles, headings, and subheadings, etc.), and, whenever possible, an attractive and compelling look and feel. A nice way to think of the user experience is to create a course theme or a brand identity for 
the course, in which one could even select a specific color palette, consistent fonts, and similar images and icons.

\section{Manage the learning spaces well}

Because in the flipped model the instructor trades off face-to-face contact time, the students should be well-guided about the expected work that needs to be done asynchronously and remotely. Undoubtedly, the flipped class model allows students to better allocate their overall time throughout the week and the entire semester. However, the students very much appreciate a well-outlined weekly course schedule in which the deadlines are clearly established and consistently followed by the instructor.

\section{Teach the students how to learn within a flipped course context}

I have found that students are usually open to new learning strategies. However, at the beginning of the semester, it is important to be clear about the reasons why one is "flipping the classroom." Explain what flipped pedagogy is, and provide them with a context that makes it very clear why your teaching philosophy and experience led to this choice. Be confident that these selected strategies are the best way to meet the defined learning outcomes.

\section{Create ungoogleable learning experiences}

You have probably mastered your teaching strategies and are skilled in how to use your face-to-face classroom time. Recording instructional videos and creating materials to be accessed by the students asynchronously should not be difficult. The most challenging component of this experience is that you will need to completely rethink how you will create your in-person time with your students after you decide to deliver content remotely. The students do not want (or need) a review section in which you will summarize the content they have already accessed remotely. Take the opportunity to lead your students into a situation that they can only escape by thinking. I like to think that every week I had to prepare a desirable, fun and, yet ungoogleable, in-person session with my students. Many times, my mantra while preparing my class was this one: If the students can Google the answers, then I may be asking the wrong questions.

\section{FINAL CONSIDERATIONS}

The global pandemic that impacted us in 2020 forced a massive and unprecedented shift to teach our students remotely. During the last two years, the entire world broke down barriers about online education and tried new ways of teaching that cannot be simply ignored moving forward. Institutions expanded their educational resources, both faculty and students acquired higher levels of digital competencies, and our student and faculty expectations about content delivery and course engagement are now very different. Whether face-to-face, hybrid, simulcasting, or fully online, we must embrace new digital tools and take the risk of adopting new pedagogical practices that allow us to experiment and reconceptualize the traditional ways of delivering instruction and educating the next generation of students.

Our students now have enhanced expectations of how content can be delivered and how learning can be assessed. They want a more elegant transition from elearning 
and face-to-face. They want educational technology that improves and enables anywhere, anytime learning. Personalized and student-led learning will inevitably lead curriculum reforms. As exemplified in this course, inquiry-based strategies will be the norm, and assessments must uncover what is really being learned. Many instructors are already engaging with students as never before through the use of discussion boards, interactive video lectures, collaborative online polling, digital whiteboarding, breakout rooms, and virtual group projects. Although we all missed the traditional on-campus and in-person experiences, I might also challenge us to recognize that our reputation for academic excellence is not necessarily constrained to making choices between online or in-person learning environments. I am confident that we can meet students' new expectations by finding ways to leverage the benefits of both learning environments moving forward.

There is no going back to the way we used to teach before the pandemic. Instructors need to start thinking about how to leverage all of the creative work that has been created to deliver content and virtually engage with our students in a manner that allows us to reimagine and reinvent the in-person learning experience. In a more practical way, we should be asking ourselves, "how do we integrate the virtual practices we learned over the last semesters to make the best use of our face-to-face time with our students moving forward?" More than ever, this is the time to shift instruction to a learner-centered model in which the time spent inside the classroom is strategically designed to be experiential and used to explore topics in greater depth, thereby creating meaningful learning opportunities for our students. In-person learning experiences must be relevant to the students' personal and professional lives. It may also be a good opportunity to think of the classroom as an open environment created in real time with (and by) the students and instructor. Start envisioning in-person sessions in which students collectively select issues and topics pertinent to modules and units, identify topics that are drawn from clinical cases, and critically analyze conflicting information freely available on the internet. The premise that only "correct information" can be used to educate our students is, at minimum, a mistake. If the real world is full of blundered information, we could surely make good use of it to develop critical thinking, especially if such content is freely accessible to our students. Ultimately, we must see this as an opportunity to connect our students with their own reality and educate them to be more literate and fluent when it comes to communication skills in the digital world.

One of the biggest mistakes that we often make in higher education is to think that all students learn from the same teaching method. To assume that one selected teaching strategy is enough to equally promote learning to all students is, undoubtedly, a common fault committed by many instructors. We know from our own experiences as apprentices that we learn more effectively when combining certain sets of strategies and methods. For example, we can learn how to deal with brand new equipment by reading the manual, listening to someone's explanation, or even watching an explanatory video. Certainly, in the end, you will come to a conclusion that one of these strategies was definitely more helpful and effective than the others. However, your peers may not equally benefit from the same "best" strategy that worked for you. One of the biggest insights that I have had during my journey was not that I needed to flip my class, but that through figuring out ways to diversify content delivery, I made my teaching more equitable, inclusive, accessible, and respectful of different ways of learning. 
Lastly, I want to thank the current editors of the Brazilian Journal of Motor Behavior for inviting me to contribute to the celebratory issue that commemorates its fifteenth anniversary. In 2006, I had the greatest privilege to co-author the very first paper published in this journal with my dear mentor and friend Dr. Jane E. Clark. At that time, we provided the readers with our view of motor behavior as a scientific field from the start of the 21st century. Fifteen years later, I offer this contribution with the intent to remind us of the progress that we also have made in the way we inspire, innovate, and impact education in the same field. Teaching is a common scholarly activity that unites us in academe. It is also the primary way in which curiosity and imagination are triggered so that the new generation of students can be inspired to start their own research program and advance the discipline forward.

While the scope of this paper is limited to my personal experience as an educator, scientist, and academic administrator, others might draw on ideas and, eventually, adapt them to different subject areas and/or co-related disciplines.-10 I strongly encourage my peers to take up the task and share the innovative work that they are doing to transform the classroom experience in higher education. I also urge higher-educational institutions to support the creative and effective use of educational technologies that enhance our students' learning and engagement--synchronously and asynchronously. It is about time for scientific societies around the world to equally value teaching innovations. Perhaps, create a special session at their annual conferences that is exclusively dedicated to educational research in the field. Due to the pandemic, all of us tirelessly worked to transform our courses. This is the perfect time to create venues that showcase best practices and, eventually, publish them in special issues or sections of journals edited by the scientific societies. To stay afloat, scholars will have to be creative, collaborate, and help administrators to optimize the use of limited institutional resources to expand access to high-quality career and technical education programs.

The new generation of students is longing for a world that is racially and economically just--a world in which resources are equitably shared. In the years to come, we need to start exploring ways to collectively share different types of digital resources that can be used in education and research around the world. For instance, as part of the membership benefits, the scientific societies could create and maintain cloud-based repositories full of curated and licensed (Creative Commons) materials such as, text, media, modules, videos, podcasts, and other digital assets that are useful for teaching, learning, and assessing, as well as for research purposes that could be made freely available to all its members. Alternatively, as part of the new Open Educational Resources (OER) movement, the societies could figure out ways to offer and promote these educational materials freely and openly for learners worldwide. As the American speculative fiction author William Gibson said once: "the future is already here--it's just not evenly distributed."

\section{REFERENCES}

1. Steed A. The fliped classroom. Teaching Business \& Economics. 2012;16,9-11.

2. Brunsell E, Horejsi M. "Fliping" your classroom. The Science Teacher. 2011; 78, 10. 
3. Long T, Cummins J, Waugh M. Use of the flipped classroom instructional model in higher education: instructors' perspectives. J Comput High Educ. 2017, 29,179-200 (2017). https://doi.org/10.1007/s12528-016-9119-8

4. Larcara M. Benefits of the flipped classroom model. In Curriculum design and classroom management: Concepts, methodologies, tools, and applications (pp. 93-105). 2015, Hershey, PA: IGI Global.

5. Hodges SH, Weber ND. Making heads or tails of classroom flipping. Kappa Delta Pi Rec. 2015,51,57-63. Doi:10.1080/00228958.2015.1023135

6. Cabı E. The impact of the flipped classroom model on students' academic achievement. Int Rev Res Open Dis. 2020,19. Doi: 10.19173/irrodl.v19i3.3482

7. Crews T, Butterfield J. Data for flipped classroom design: Using student feedback to identify the best components from online and face-to-face classes. High Educ Stud. 2014,4,38-47.

8. Ayçiçek B, Yelken TY. The effect of flipped classroom model on students' classroom engagement in teaching English. Int J Instr. 2018, 11,385-398.

Doi:10.12973/iji.2018.11226a

9. Tune J, Sturek M, Basile D. Flipped classroom model improves graduate student performance in cardiovascular, respiratory, and renal physiology. AJP Adv Physiol Educ. 2013,37,316-320. Doi:10.1152/advan.00091.2013

10. Steinel NC, Corliss S, Lee M. Engagement with in-class activities contributes to student success in an accelerated, flipped classroom, Medical School Immunology Course. $J$ Immunol. 2021, 206 (1 Supplement) 54.12.

\section{ACKNOWLEDGMENTS}

I would like to thank my colleagues at the University of Maryland, Dr. Jane E. Clark, Professor Emerita in the School of Public Health, and Deb Mateik, Director of Learning Technology Design, for being such strong supporters and partners during my journey to experiment and redesign this course over the years. I also want to express my gratitude to both of them, as well as Dr. Megan Masters, Director of Academic Technology Experience, and Megan Speakes, Communication and Marketing Specialist, for their willingness and availability to review and provide feedback on this manuscript. This work was partially funded by UMD's Blended Teaching Innovation Grant, an initiative from the Office of Senior Vice President and Provost (2011). 
Citation: Oliveira MA. (2021). Creating Ungoogleable Learning Experiences: An experiment with a course in motor development. Brazilian Journal of Motor Behavior, 15(5): 429-445.

Editors: Dr Fabio Augusto Barbieri - São Paulo State University (UNESP), Bauru, SP, Brazil; Dr José Angelo Barela São Paulo State University (UNESP), Rio Claro, SP, Brazil; Dr Natalia Madalena Rinaldi - Federal University of Espírito Santo (UFES), Vitória, ES, Brazil.

Copyright:@ 2021 Oliveira and BJMB. This is an open-access article distributed under the terms of the Creative Commons Attribution-Non Commercial-No Derivatives 4.0 International License which permits unrestricted use, distribution, and reproduction in any medium, provided the original author and source are credited.

Funding: This research did not receive any specific grant from funding agencies in the public, commercial, or not-forprofit sectors.

Competing interests: The authors have declared that no competing interests exist.

DOI: https://doi.org/10.20338/bjmb.v15i5.262 